\title{
Interconexões Setoriais e PIB per capita: há relação direta entre ambas as variáveis?
}

\section{Gabriel Dias da Silva}

Mestre em Economia - Universidade Federal de Juiz de Fora Endereço: Campus Universitário - Rua José Lourenço Kelmer, s/n - São Pedro - Juiz de Fora /MG CEP: 36036-900 - E-mail: gabriel.dias.iee@hotmail.com - https://orcid.org/0000-0003-2677-2618

\section{Fernando Salgueiro Perobelli}

Professor - Universidade Federal de Juiz de Fora

Endereço: Campus Universitário - Rua José Lourenço Kelmer, s/n - São Pedro - Juiz de Fora /MG

CEP: 36036-900 - E-mail: fernando.perobelli@ufjf.edu.br - https://orcid.org/0000-0003-2364-8865

Recebido: 25/05/2016. Aceite: 23/11/2017.

\section{Resumo}

Desde que autores como Perroux (1955) e Hirschman (1958) propuseram a fomentação de ligações intersetoriais como estratégia para o crescimento econômico, alguns países de menor renda buscaram o desenvolvimento industrial, enquanto que nos mais ricos observaram-se processos de desindustrialização e crescimento de importância dos serviços. Seguindo essa contextualização, este trabalho avalia as relações que o total de interconexões dentro de uma economia poderiam ter com o PIB per capita e sua taxa de crescimento. Assim, a partir de dados de insumo produto de 40 países para os anos entre de 1995 e 2011 , foram construídas medidas agregadas de ligações (MAL) totais, dos setores primários, industriais e de serviços, avaliadas com o auxílio da técnica de análise de agrupamentos. Os resultados revelam tendências de redução nas conexões dos setores industriais, sua associação positiva com o crescimento do PIB per capita, e crescimento da integração dos serviços com as demais atividades.

\section{Palavras-Chave}

Economia regional. Crescimento econômico. Integração produtiva.

\begin{abstract}
Since authors as Perroux (1955) and Hirschman (1958) proposed the fostering of intersectoral links as a strategy for economic growth, some lower-income countries sought industrial development, while in the richer we found de-industrialization and growth importance of services. Following this context, this study evaluates the relation that the total interconnections within an economy could have with GDP per capita and its growth rate. So, from input-output data from 40 countries for the years 1995 and 2011, aggregate measures of links (MAL) were built and evaluated for total and for primary, industrial and service sectors. The results show a reduction trend in connections of industrial sectors, its positive association with the growth of GDP per capita and the integration of services with other activities.
\end{abstract}

- Os autores agradecem ao financiamento da CAPES, CNPq e FAPEMIG para realização deste trabalho. Esta obra está licenciada com uma Licença Creative Commons Atribuição-Não Comercial 4.0 Internacional. 


\section{Keywords}

Regional economics. Economic growth. Productive integration.

\section{JEL Classification}

O40. R11. R15. R58.

\section{Introdução}

Na década de 1950, autores como Perroux (1955), Rasmussen (1956), Hirschman (1958) e Chenery \& Watanabe (1958) propuseram estratégias para o crescimento que tinham como base o fomento às ligações internas entre os setores via consumo intermediário. Em especial, Hirschman (1958) propõe que os efeitos de ligação, ou linkages, podem ser usados para detectar atividades que seriam pontos ótimos para investimentos, dada sua capacidade de fornecimento e de estímulo à produção de outras indústrias via compra de insumos. Indústrias como essa capacidade foram chamadas de "setor chave" por Perroux (1955) e Rasmussen (1956). Como a presença desse tipo de setor seria uma característica de países de maior PIB per capita, Perroux (1955), Chenery \& Watanabe (1958) e Hirschman (1958) defendem que nesses lugares haveria um agregado maior de ligações em comparação com as demais regiões, ou seja, também haveria uma relação direta entre o total de interconexões em um país e seu nível de PIB per capita.

Desde a época em que foram publicadas as obras dos autores supracitados, a maioria dos países passou por diversas transformações em suas estruturas econômicas, a destacar o papel e composição no produto das atividades primárias, manufatureiras e de serviços. Em geral, observou-se o ganho de relevância do setor terciário em grande parte dos países, ao mesmo tempo que muitos deles também tiveram processos de desindustrialização (Cuadrado-Roura 2013; Capello \& Fratesi 2013; Garcilazo, Mouradian \& Oliveira 2013).

Contudo, as características dessas transformações foram diferentes entre os países, o que estaria relacionado com o nível do seu PIB per capita. Por um lado, nos países com maior PIB per capita, notou-se que a evolução dos serviços foi acompanhada por maior integração com a indústria, fazendo com que essas atividades tomassem também a função de insumos interme- 
diários. Ainda nesse grupo de países, devido às mudanças organizacionais na produção, a desindustrialização tem como uma de suas causas a segmentação da produção, pela qual observou-se o deslocamento de etapas de produção para lugares onde sua realização é mais vantajosa. Os países de menor nível de renda per capita, além de em geral poderem ser receptores dessas etapas, tiveram o crescimento dos setores terciários sendo explicado majoritariamente por movimentos de pressão de oferta de mão de obra (Weller 2004; Schettktat \& Yocarini 2005; Maroto-Sanchez 2010; Feenstra 2002; Markusen 2002; Capello \& Fratesi 2013). É plausível que essas mudanças tenham alterado o modo como o total de interconexões se relaciona com o tamanho do PIB per capita dos países, sendo necessária uma investigação para identificar se os novos padrões de estrutura econômica apontados pela literatura se refletem nessa variável. Essa análise é a proposta deste artigo.

Aplicando o método do autovetor de Dietzenbacher (1992), pode-se calcular o total de interconexões de forma comparável entre os países, tornando-se possível promover essa averiguação. Além de se obter os índices agregados, também se pode dividir os valores para os setores primários, industriais e de serviços. Nos resultados, apesar de não ter sido possível verificar a relação entre o total de ligações intersetoriais e o PIB per capita de um país, as desagregações feitas no cálculo dos linkages possibilitou constatar que em aproximadamente $75 \%$ dos países, em cada caso, houve aumento da integração dos serviços com os demais setores econômicos e queda nas ligações internas tanto das manufaturas quanto dos setores primários entre os anos de 1995 e 2011.

Ainda, com os valores encontrados para os índices gerais de conexões, foi realizada uma análise de agrupamentos para classificar os países de acordo com o seu nível de PIB per capita e o total de ligações. Com essa ferramenta, mais uma vez não foi possível encontrar evidências de relação entre o PIB per capita dos países e a quantidade de conexões intersetoriais que eles têm. Por outro lado, verificou-se que uso da estratégia proposta por Perroux (1955), Rasmussen (1956), Hirschman (1958) e Chenery \& Watanabe (1958) ainda é atual, já que taxas maiores de crescimento do PIB per capita parecem estar associadas a valores elevados na medida agregada de ligações industriais. 
O presente artigo está dividido em 6 seções, contando com esta introdução. Na segunda parte é feita uma revisão na literatura sobre as interconexões setoriais e seu efeito sobre o crescimento econômico, e das mudanças estruturais pelas quais os países passaram. Na terceira seção são apresentadas as metodologias do método do autovetor e da análise de agrupamentos. A quarta seção apresenta a base de dados e a quinta discute os resultados encontrados. Finalmente, a sexta seção conclui o artigo.

\section{Referencial}

A partir da década de 50, os estudos relacionados ao crescimento ${ }^{1}$ econômico passaram a atentar para a relevância dos fluxos intersetoriais de mercadorias. $\mathrm{O}$ fomento de ligações entre os setores via o fornecimento de insumos, ou seja, em uma relação de consumo intermediário, ganhou destaque como estratégia de crescimento econômico a ser seguida pelos países (Perroux 1955; Rasmussen 1956; Hirschman 1958; e Chenery \& Watanabe 1958). Isso porque alguns setores teriam a capacidade de estimular a produção de outros setores, ou até mesmo do restante da economia, pelo aumento de sua produção (Perroux 1955). Aqui, dois efeitos são possíveis de serem vistos: a necessidade de compra de insumos traria incentivos à realização de produção doméstica para seu fornecimento; também, a maior quantidade de mercadorias produzidas, no caso de sua possível utilização como bem intermediário, encorajaria o estabelecimento da produção interna que usa esse bem como insumo por causa da presença de fornecedores domésticos estáveis e seguros. Esses efeitos foram chamados respectivamente por Hirschman (1958) de backward linkage effects e forward linkage effects.

Na argumentação de Perroux (1955), uma indústria que tem o poder de induzir uma elevação geral nas compras e vendas de uma economia nacional como um todo é chamada de "indústria chave". A mesma alcunha é dada por Rasmussen (1956) para os setores que ao se aumentar a demanda por seus produtos, o impacto sobre o conjunto industrial e a economia como um todo seria maior em relação às demais indústrias. Chenery \& Watanabe (1958) aplicam os conceitos de "extensão do uso indireto de

1 Nesta seção, "crescimento" e "desenvolvimento" econômicos podem aparecer como sinônimos, tal como a forma como foram tratados pelos autores referenciados. 
fatores" e "demanda indireta por fator" para identificar setores ditos como "intermediários", que teriam altos valores nesses coeficientes. O ponto comum em relação à argumentação nesses quatro trabalhos é que os setores "chave", "intermediários" ou com alta capacidade de emanar efeitos de ligação são vistos como pontos preferencias de investimento em políticas de desenvolvimento.

Com base nos conceitos desenvolvidos, houve tentativas de se estabelecer relações entre o PIB per capita dos países e a configuração de sua base industrial, no que diz respeito as ligações existentes entre elas. Perroux (1955), por exemplo, conclui que nas economias mais ricas as "indústria chave" são mais presentes. Chenery \& Watanabe (1958) defendem que nos países com maior PIB per capita há maior quantidade de "setores intermediários", aqueles que têm mais interconexões. Para Hirschman (1958), países de menor PIB per capita teriam maior especialização em setores primários, como as atividades agrícolas e de extração, e em indústrias nas quais apenas etapas finais de produção são feitas, realizando importação de insumos em estágio quase pronto. No primeiro caso, além de haver pouca possibilidade de apresentar linkages para trás, grande parte do produto agrícola é destinado para o consumo final. No segundo, devido à importação, não existem ligações para trás, ao mesmo tempo em que os bens finalizados são destinados para o consumo.

Seguindo isso, Hirschman (1958) defende que para alcançar maior nível de crescimento econômico, é desejável que esses países não se especializem nos setores primários, além de buscar o estabelecimento de indústrias de estágio anterior as que já estão presentes, estimulando a criação de interconexões entre essas atividades. Para ele, as interconexões desempenham um papel tão grande para o crescimento que, como ele sugere, ao se ranquear países pela sua proporção de transações intersetoriais com o seu produto total, esse ordenamento teria correlação próxima a um ranking do nível per capita desses mesmos países. Assim, propõe que há relação direta do total de interconexões de um país com o tamanho de seu PIB per capita. Dessa forma, conclui que a falta de linkages é uma característica típica de países com baixo PIB per capita.

Contudo, desde que o estabelecimento da possível existência de correlação positiva entre a quantidade de conexões intersetoriais dos países com o seu PIB per capita, até os dias de hoje, a estrutura econômica mundial passou por constantes transformações. Se por um lado o setor de serviços 
cresceu continuamente e passou a ser o mais relevante tanto em termos de produto quanto de emprego na maioria dos países (Wölfl 2005; Schettkat \& Yocarini 2006; Maroto-Sanchez 2010), a principal contrapartida foi a perda de participação relativa do emprego nas manufaturas, em um processo chamado de desindustrialização (Rowthorn \& Ramaswany 1997).

Tais movimentos não apresentam uma única e simples explicação, mas sim uma diversidade de fatores que tiveram alguma influência. Alguns deles ajudam a entender simultaneamente ambos os processos. As primeiras tentativas de esclarecimento passavam pela diferença relativa de aumento na produtividade dos setores de serviços em comparação com os de manufaturas, ao mesmo tempo em que as tendências de custo do fator trabalho seriam uniformes (Kaldor 1961; Baumol 1967; Kuznetz 1971; e Maddison 1980). Uma segunda posição alude à Lei de Engel para argumentar que conforme aumenta a renda das famílias de um país, como consequência da elevação do seu PIB per capita, eleva-se a proporção de consumo de bens supérfluos (em geral serviços) em detrimento de bens de consumo (manufatureiros), o que é explicado pelo diferencial de elasticidade-renda da demanda entre ambos (Schettktat \& Yocarini 2006).

As mudanças produtivas e organizacionais pelas quais as empresas passaram também têm um papel relevante no processo. Wölfl (2005), MarotoSanchez (2010) e Cuadrado-Roura (2013) destacam, nesse caso, os processos de "terceirização" e "servicificação" das manufaturas. Na prática, grande parte das indústrias passaram a necessitar de mais serviços para a produção, comercialização e distribuição de seus bens, além da resolução de problemas legais e fiscais. Como consequência, os serviços estriam cada vez mais integrados aos bens e ao restante do sistema produtivo.

Um terceiro processo que concerne a mudanças organizacionais nas empresas é relativo à "desintegração da produção". Como corolário da evolução nas tecnologias de informação e comunicação (TIC) e nos transportes, tornou-se viável a consideração de outros fatores na decisão do local de realização de uma atividade produtiva (Feenstra 1998). Com isso, firmas passaram a ter a possibilidade de deslocar etapas produtivas para outras regiões ou países, sob o incentivo das diferenças de preços de fatores entre eles. Consequentemente, intensificou-se a possibilidade de as firmas se tornarem multinacionais, mantendo sua matriz no país de origem enquanto que suas instalações de produção são deslocadas para um ou mais países. 
Evidências disso são verificadas no aumento do comércio de bens intermediários e do investimento direto externo internacional (OMC 2014).

Um dos resultados, então, da segmentação da produção foi uma evolução na divisão internacional do trabalho com o aumento no comércio NorteSul. Segundo Feenstra (2002), Keller (2010) e Grossman \& Helpman (2002a, b), atividades menos tecnologicamente complexas e mais padronizadas têm maior tendência para ser segmentada, saindo dos países com maior PIB per capita em direção aos com menor, o que também é diretamente proporcional à redução nos custos de transporte e importação. Funcionam ainda como incentivos à segmentação um bom ambiente institucional e infraestrutural, e o tamanho do mercado no possível receptor da atividade. De fato, observou-se que as economias de maior PIB per capita (do norte) produzem e exportam manufaturas intensivas em trabalho qualificado. Por outro lado, cabe aos países de menor PIB per capita a produção e exportação bens intensivos em trabalho de menor qualificação e mais rotinizados (Rowthorn \& Ramaswamy 1999).

Há, finalmente, alguns fatores complementares que influenciaram o ganho de participação dos serviços nas economias. Por exemplo, a evolução nas tecnologias de informação e computação, além de permitir o aparecimento de novos serviços, cooperou para o surgimento de novas formas de realizar os já existentes, impactando positivamente sua produtividade, levando a melhorias na sua qualidade, redução no tempo necessário para sua produção e redução da distância entre produtor e consumidor (Maroto-Sanchez 2010; Cuadrado-Roura 2013). Ainda, são sublinhados os processos de urbanização, a entrada das mulheres no mercado de trabalho, o envelhecimento da população, a incorporação dos mais jovens ao mercado consumidor, a procura por ascensão no padrão de vida como consequência do desenvolvimento e modernização social (Wölfl 2005), na demanda do setor público, cada vez mais responsável pelo bem-estar social da população, e a maior abertura e liberalização econômica, contemplando atividades como as de transporte, financeiros, turismo e consultorias, dentre outros (CuadradoRoura 2013).

Em todo caso, é possível apontar as principais diferenças no desenvolvimento dos serviços e no processo de desindustrialização entre os países com maior e menor PIB per capita e conjecturar os seus impactos sobre o total de interconexões de cada grupo de países. Para o primeiro agrupamento, em se tratando dos serviços, Schettktat \& Yocarini (2006) e 
Maroto-Sanchez (2010) apontam como característica maiores integrações e relações observáveis com os setores manufatureiros. Por isso, é de se esperar que seus índices de linkages com os demais setores mostrem aumentos. Para a indústria, Rowthorn \& Coutts (2013) explicam que esses países passam por um processo classificado como "desindustrialização positiva", seguindo uma relação de "u invertido" entre a participação da indústria e o PIB per capita das economias. Isso quer dizer que após um certo estágio de crescimento, é natural que o emprego da indústria comece a perder participação (e.g. lei de Engel). Ainda, com a segmentação da produção, a saída de etapas intermediárias de produção reduz a integração vertical. Dessa forma, é natural que os indicadores de ligações entre os setores manufatureiros tenham se reduzido. Apesar disso, deve-se salientar que a indústria nesses países continua crescendo em termos absolutos, com alto nível de investimento, competitividade e elevação de produtividade.

A observação sobre os países de menor PIB per capita é mais complicada e heterogênea, devendo se basear no seu estágio de evolução, ou seja, em que ponto ela está na curva de "u invertido". Conforme observado por Weller (2004), o crescimento do setor terciário baseia-se principalmente em pressões por parte da oferta de mão de obra, gerada por processos simultâneos de inclusão e exclusão de trabalhadores, sendo assim esperado que suas conexões com os demais setores tenha, comparativamente, menor aumento. Quanto a indústria, a queda na participação do emprego nas manufaturas pode acontecer após um deslocamento nas dotações de bens primários (tal como descoberta de petróleo e gás), ou depois do desenvolvimento de superávits comerciais significativos nos serviços, especialmente em áreas como turismo e finanças. Mas deve-se lembrar que alguns desses países, principalmente os na fase ascendente, além de serem receptores de etapas manufatureiras provenientes da segmentação da produção, o estímulo à industrialização e a fomentação de conexões pode ainda ser uma estratégia de crescimento e, por isso, ainda devem mostrar ganhos nas conexões entre indústrias. 


\section{Metodologia}

\section{1. Índices de Ligações}

Para avaliar a relação entre o PIB per capita dos países e seu total de interconexões, deve-se fazer uso de um índice que consiga agregar o total de linkages que existe dentro de uma economia. O método do autovetor, de Dietzenbacher (1992), índica que os elementos do vetor de Perron ${ }^{2}$ da matriz de coeficientes técnicos, ${ }^{3}$ calculados a partir de uma matriz de insumo-produto nacional, podem ser usados para a mensuração de linkages. No caso, os índices de ligação para frente e para trás são representados, respectivamente, pelos vetores de Perron de lado direito e de lado esquerdo. ${ }^{4}$

Os índices apresentados, nesse caso, são para setores individuais. Contudo, como um dos corolários do método, Ditzenbacher (1992) demonstra que o autovalor dominante $\lambda$ dessa mesma matriz de coeficientes técnicos pode ser usado como um indicador global (ou agregado) de linkages. Para a demonstração formal, considere duas matrizes de produção primitivas $\boldsymbol{B}_{1}$ e $\boldsymbol{B}_{2},{ }^{5}$ representativas de dois países hipotéticos 1 e 2 , com autovalores dominantes $\lambda_{1}$ e $\lambda_{2}$ e vetores de Perron de lado direito $\boldsymbol{z}_{1}$ e $\boldsymbol{z}_{2}$ respectivamente.

Referenciando o trabalho de Seneta (1981), Dietzenbacher (1992) afirma que:

$$
\lim _{k \rightarrow \infty} \mu^{-k} \boldsymbol{B}_{1}^{k}=0
$$

para todos seus elementos se e somente se $\mu>\lambda_{1}$, com $k$ indicando o número de etapas do processo produtivo. Também, que

$$
\lim _{k \rightarrow \infty} \lambda_{1}^{-k} \boldsymbol{B}_{1}^{k}=\boldsymbol{z}_{1} \boldsymbol{q}_{1}
$$

2 Pelo teorema de Perron-Frobenius, uma matriz real quadrada com entradas positivas tem apenas um único maior autovalor. O autovetor correspondente a esse autovalor, chamado de vetor de Perron, possui componentes estritamente positivos.

3 Seja $\boldsymbol{X}$ uma matriz nxn de fluxos intersetoriais e $\boldsymbol{x}$ um vetor coluna de produção total, a matriz $\mathbf{A}$ de coeficientes técnicos é definida por $\boldsymbol{A}=\boldsymbol{X} \widehat{\boldsymbol{x}}^{-1}$, onde ${ }^{\wedge}$ denota uma matriz diagonal.

4 Para a demonstração formal, ver Dietzenbacher (1992:420-423).

5 Seja $\boldsymbol{X}$ uma matriz $n x n$ de fluxos intersetoriais e $\boldsymbol{x}$ um vetor coluna de produção total, a matriz $\mathbf{B}$ de produção é definida por $\mathbf{B}=\widehat{\boldsymbol{x}}^{-1} \boldsymbol{X}$, onde ${ }^{\wedge}$ denota uma matriz diagonal. 
para todos seus elementos, onde $\boldsymbol{q}_{1}$ é o vetor de Perron de lado esquerdo de $\boldsymbol{B}_{1}$ e $\boldsymbol{q}_{z}^{\prime}=1$. Agora, denote o $i$ - ésimo elemento do vetor $\boldsymbol{B}_{1}^{k} \boldsymbol{e}$ como $\left(\boldsymbol{B}_{1}^{k} \boldsymbol{e}\right)_{i}$ e suponha que $\lambda_{2}>\lambda_{1}$.

Então:

$$
\frac{\left(\boldsymbol{B}_{1}^{k} \boldsymbol{e}\right)_{i}}{\left(\boldsymbol{B}_{2}^{k} \boldsymbol{e}\right)_{i}}=\frac{\left[\lambda_{1}^{-k}\left(\boldsymbol{B}_{1}^{k}\right)_{i}\right]}{\left[\lambda_{2}^{-k}\left(\boldsymbol{B}_{2}^{k}\right)_{i}\right]}
$$

onde $\boldsymbol{e}$ é um vetor de somatório de coluna em que cada $e_{i}=1$.

Nesse caso, como $\lambda_{2}>\lambda_{1}$, por (4), o numerador se aproxima de 0 quando $k \rightarrow \infty$. Por outro lado, por (5), o denominador tende a $c\left(\boldsymbol{z}_{2}\right)_{i}$, onde é um escalar. Como ambos os limites valem para todos os elementos de $\boldsymbol{B}$, o resultado se mantém para $i=1, \ldots, n$. Consequentemente, a proporção da produção que se mantém após k etapas do processo produtivo $\left(\boldsymbol{B}^{k} e\right)$ é maior para o país 2 do que para o país 1 , conclusão que se mantém para o caso das conexões para trás. O que isso significa é que um valor mais elevado para o autovalor dominante indica um agregado de linkages mais fortes, considerando ambas as direções. Em outras palavras, quanto maior for $\lambda$, maior proporção do produto que ainda está no processo produtivo após $\mathrm{k}$ etapas de produção. De forma análoga, o uso da matriz $\boldsymbol{A}$ no lugar da matriz $\boldsymbol{B}$ para o cálculo do autovalor dominante também fornece uma medida geral dos linkages, ${ }^{6}$ mas com a interpretação de que quanto maior for $\lambda$, maior a proporção do produto que é destinada para o uso intermediário. ${ }^{7}$

A metodologia do autovetor também tem a capacidade de identificar clusters (ou agrupamentos) setoriais que têm maior ou menor conexão com o restante da economia de um país. Para visualizar isso, tome como exemplo a matriz A de insumos, a seguir:

$$
\boldsymbol{A}=\left(\begin{array}{cc}
\boldsymbol{A}_{!} & \mathbf{0} \\
\boldsymbol{C} & \boldsymbol{A}_{2}
\end{array}\right)
$$

6 Segundo Dietzenbacher (1992), os valores calculados para o autovalor dominante a partir das matrizes A ou B devem coincidir.

7 Para exemplos de aplicação do método, ver Dietzenbacher (1992), Midmore, Munday \& Roberts (2006), Lopes Dias e Amaral (2008), Botric (2013) e Luo (2013). 
Onde $A_{1}$ e $A_{2}$ são quadradas, não negativas, irredutíveis e com autovalores dominantes menores do que 1 , e $\boldsymbol{C}>0$. Com esses pressupostos, garante-se que $\left(\boldsymbol{I}-\boldsymbol{A}_{1}\right)^{-1},\left(\boldsymbol{I}-\boldsymbol{A}_{2}\right)^{-1}$ e $\boldsymbol{D}=\left(\boldsymbol{I}-\boldsymbol{A}_{2}\right)^{-1} \boldsymbol{C}\left(\boldsymbol{I}-\boldsymbol{A}_{2}\right)^{-1}$ são estritamente positivas. A forma particionada da matriz inversa de Leontief, para esse caso, se torna:

$$
(\boldsymbol{I}-\boldsymbol{A})^{-1}=\left(\begin{array}{cc}
\left(\boldsymbol{I}-\boldsymbol{A}_{1}\right)^{-1} & \mathbf{0} \\
\boldsymbol{D} & \left(\boldsymbol{I}-\boldsymbol{A}_{2}\right)^{-1}
\end{array}\right)
$$

Assim, há dois grupos distintos (1 e 2). Pode-se notar que essa estrutura indica que os setores do grupo 1 não têm linkages para frente com os do grupo 2 (consequentemente, os setores do grupo 2 não têm linkages para trás com os do grupo 1). Dessa forma, todas as ligações para frente no grupo 1 permanecem dentro desse mesmo grupo. Analogamente, todas as ligações para trás da segunda aglomeração restringem-se apenas a ela própria. Agora, considere os vetores de Perron de lados direito e esquerdo de $\boldsymbol{A}(\boldsymbol{q}$ e $\boldsymbol{y})$ e faça com que $\boldsymbol{q}_{1}, \boldsymbol{q}_{2}, \boldsymbol{y}_{1}$ e $\boldsymbol{y}_{2}$ denotem as formas particionadas desses vetores. Remetendo-se a Dietzenbacher (1991), esse autor enuncia que se $\lambda$ for o autovalor dominante de:

$$
\begin{aligned}
& \text { i) } \boldsymbol{A}_{1} \text {, então } \boldsymbol{q}_{2}=\mathbf{0} \text { e } \boldsymbol{q}_{1}, \boldsymbol{y}_{1} \text { e } \boldsymbol{y}_{2}>>\mathbf{0} \text {; } \\
& \text { ii) } \boldsymbol{A}_{2} \text {, então } \boldsymbol{y}_{1}=\mathbf{0} \text { e } \boldsymbol{q}_{1}, \boldsymbol{q}_{2} \text { e } \boldsymbol{y}_{2}>>\mathbf{0}
\end{aligned}
$$

iii) Ambos $\boldsymbol{A}_{1}$ e $\boldsymbol{A}_{2}$, então $\boldsymbol{q}_{2}$ e $\boldsymbol{y}_{1}=\mathbf{0}$ e $\boldsymbol{q}_{1}$ e $\boldsymbol{y}_{2}>\boldsymbol{>} \mathbf{0}$

Lembrando que os vetores de Perron são únicos a menos de um escalar múltiplo. Com isso, Dietzenbacher (1992) demonstra que, em casos onde a matriz $\boldsymbol{A}$ de insumos é redutível, os vetores de Perron $\boldsymbol{q}$ e $\boldsymbol{y}$ contém elementos que são iguais a 0 . Mais que isso, é possível saber precisamente, a partir das afirmativas i, ii e iii, quais serão os elementos iguais a 0 . A consequência disso é a utilidade dos vetores de Perron para a triangulação de matrizes. Considere, por exemplo, que há uma permutação factível na ordem dos setores que faz com que a matriz de insumos assuma uma estrutura hierárquica semelhante a de (7). Então, a consideração dos elementos nulos e positivos dos vetores de Perron de lados esquerdo e direito da matriz $\boldsymbol{A}$ original não só irá indicar a existência dessa hierarquia, como também determinará a possível permutação de setores que levará a estrutura 
hierárquica de $\boldsymbol{A}$. Além disso, no caso da primeira afirmação, a primeira aglomeração domina a segunda em termos de maior agregado de linkages. Isso quer dizer que há um total maior de conexões para frente e para trás no primeiro grupo do que no segundo. Também, que suas ligações internas são substanciais, assim como o fornecimento de insumos intermediários da segunda aglomeração para a primeira. Interpretações análogas podem ser tiradas da segunda e da terceira afirmações. Dietzenbacher (1992) também demonstra que os vetores de Perron ainda são os vetores limites de $\boldsymbol{e}^{\prime} \boldsymbol{A}^{k} /\left(\boldsymbol{e}^{\prime} \boldsymbol{A}^{k} \boldsymbol{e}\right)$ e $\boldsymbol{A}^{k} \boldsymbol{e} /\left(\boldsymbol{e}^{\prime} \boldsymbol{A}^{k} \boldsymbol{e}\right)$, validando a utilidade dos resultados acima.

Dietzenbacher (1992) destaca que casos em que os elementos de $\boldsymbol{y}_{1}$ e $\boldsymbol{q}_{2}$ são iguais a zero são extremos. Entretanto, mesmo quando os valores se aproximam mas não alcançam essa marca, as afirmações i, ii e iii seriam de grande importância porque com elas é possível identificar clusters de setores que são relativamente independentes do restante da economia. A colaboração dessa última característica do método do autovetor para esse estudo se dá pela possibilidade de separar o total de ligações dentro de cada um dos grandes setores - os primários, as manufaturas e os serviços ao permutar ao ponto de considerá-los como clusters separados. Em outras palavras, para cada país, será possível computar o total de interconexões dentro apenas dos setores primários ou das manufaturas, por exemplo. Nesse caso, abre-se a possibilidade de verificar a evolução do total de conexões dentro da indústria ou da integração dos serviços com o restante da economia com o passar dos anos. A partir disso, foram construídas as seguintes variáveis: a) Medida agregada de ligações (MAL total): É o total de interconexões entre todos os setores de uma economia, calculada pelo autovalor dominante da matriz de produção; b) Medida agregada de ligações dos setores primários (MAL agr): É o total de interconexões entre apenas os setores primários. Foi construída com o cômputo do autovalor dominante da matriz de produção considerando apenas os setores primários; c) Medida agregada de ligações dos setores industriais (MAL ind): É o total de interconexões entre apenas os setores industriais. Calculada pelo autovalor dominante da matriz de produção considerando apenas os setores industriais; e d) Medida agregada de ligações dos setores de serviços (MAL ser): É o total de interconexões dos setores de serviços. Computada pelo autovalor dominante da matriz de produção considerando todas as compras e vendas intermediários dos setores de serviços. 
O objetivo com essas variáveis é a comparação temporal e entre países para os valores obtidos em cada uma delas, além da possibilidade de se verificar qual dos três grandes setores apresenta maior nível de conexões internas. Dessa forma, também é possível observar mudanças estruturais nas economias na medida em que um agrupamento perde importância relativa a outro com o passar do tempo. Finalmente, a escolha de se calcular todas as interconexões dos setores de serviços se deu porque dessa forma consegue-se avaliar a integração desse setor com o restante da economia, enquanto que nos demais apenas se analisa internamente.

\subsection{Análise de Agrupamentos}

A análise de agrupamentos é uma ferramenta pela qual se pode identificar padrões mais difíceis de serem observados visualmente. Essa análise é uma técnica multivariada descritiva que consiste na classificação de objetos (pessoas, países, espécies, etc) em grupos de acordo com suas características (variáveis), aplicando um método que garanta a existência de alta homogeneidade interna aos grupos, enquanto que entre os agrupamentos formados se tem elevada heterogeneidade. Para esse objetivo, devem ser tratadas questões tais como a forma de medir a distância entre os objetos (similaridade entre as observações ao longo das variáveis), de formar os agrupamentos, e o número ideal de grupos.

O método escolhido para a definição dos agrupamentos é o híbrido (dois estágios), que tem vantagem de unir os benefícios dos métodos hierárquico $^{8}$ e não hierárquico. ${ }^{9}$ Nesse método, primeiro aplica-se a técnica hierárquica para a definição do número de grupos e dos centros iniciais. Nessa etapa, será usado o método de agrupamento de Ward, que mede a distância entre dois agrupamentos como a soma dos quadrados entre eles, feitos para todas as variáveis. Sua grande vantagem é a capacidade de minimizar diferenças internas entre grupos, comparado com outros métodos.

8 No método hierárquico (aglomerativo), a cada etapa, um objeto ou um agrupamento se une a outro objeto ou agrupamento, de acordo com seu grau de semelhança medido pela forma de avaliação de distância escolhida.

9 No método não hierárquico, define-se previamente o número de agrupamentos e cada objeto vai sendo designado a um grupo, de acordo com a melhor solução possível para essa quantidade de grupos. Nesse caso, seleciona-se a posição do centro inicial de cada agrupamento, e os objetos dentro de uma distância preestabelecida são incluídos no grupo resultante. Esse procedimento de escolha de um centro inicial é repetido diversas vezes e os objetos podem ser deslocados para outros agrupamentos, se estiverem mais próximos deles. 
Em seguida, executa-se o método não hierárquico para designar as observações para os grupos, segundo a quantidade e pontos centrais definidos. Dessa forma, a vantagem de se estabelecer o número de agrupamentos pelo método hierárquico é complementada pela capacidade do método não hierárquico de refinar os resultados pela possibilidade de alteração de pertinência de um objeto a um determinado grupo. A distância entre os objetos será medida pela distância euclidiana quadrática, a mais recomendada para utilização conjunta com o método de Ward. Ainda, foi feita a padronização das variáveis pelo escore $Z$ (ou padrão), já que há diferentes escalas para as variáveis, o que poderia afetar os resultados.

Para a escolha do número ideal de agrupamentos não há um método convencionado, e por isso deve-se seguir um conjunto de instruções: inspirar-se em teorias preestabelecidas, que podem sugerir uma quantidade específica de agrupamentos; ter-se um número de grupos adequado para que se consiga extrair informações relevantes deles; observar quando a medida de similaridade apresenta um salto muito grande no momento em que dois conjuntos são unidos, indicando que dois agrupamentos com características distintas estão sendo aglomerados (regra da parada). Nesse último caso, recomenda-se como a melhor solução aquela antes do grande salto. Ainda, é indicado o cômputo de mais de uma solução, como forma de qualificar os resultados.

\section{Base de Dados}

O grande obstáculo para a realização de trabalhos com comparações de níveis de ligação de diferentes países era a disponibilidade de matrizes insumo-produto padronizadas. Essa barreira foi superada com o projeto World Input-Output Database (WIOD), organizada pela Diretoria Geral de Pesquisa da Comissão Europeia, e que construiu matrizes de insumo -produto para 40 países (mais uma agregação para o restante do mundo) e 35 setores para o período entre 1995 e 2011. O período e a amostra avaliados nessa dissertação seguem os dados disponibilizados pela WIOD, com as listagens dos países e setores podendo ser vistas nos anexos I e II, respectivamente. As informações nessas matrizes estão registradas em Dólares do ano corrente, tendo sido utilizadas as taxas de câmbio oficiais disponibilizadas pelo Fundo Monetário Internacional (FMI) para a con- 
versão, e em preços básicos (que excluem impostos líquidos e margens de comércio e transporte, alocadas como o produto dos setores de comércio e transporte, respectivamente). ${ }^{10}$ Já o PIB per capita teve como fonte a base de dados do Banco Mundial.

\section{Resultados}

\subsection{Medidas Agregadas de Ligações}

Na Tabela 1 são apresentados os valores encontrados para a medida agregada de ligação total nos anos de 1995 e 2011. Com esses números, foi obtida a variação total entre os dois períodos e o ordenamento dos países em ordem descrecente de integração interna. Ainda, é exibido o ranqueamento dos países de acordo com o seu PIB per capita em 2011 e a variação anual média nessa variável entre os anos de 1995 e 2011. Em 21 países o total de conexões diminuiu, sendo que 9 deles ocupavam a metade superior no ordenamento do PIB per capita. Já dentre os 19 países que elevaram sua integração total, 11 estavam entre os 50\% mais ricos da amostra. Portanto, observa-se nesse caso uma certa aleatoriedade, ou seja, não parece ser possível dizer se há um padrão dentre os países que aumentaram ou diminuíram o total de suas interconexões no período analisado. Um segundo ponto é que dos 19 países que mostraram aumento em sua integração, 13 estavam entre os 20 primeiros no ranqueamento para essa variável. Similarmente, dos 21 que mostraram queda, 14 estavam entre os 20 últimos. Assim, parece haver uma pequena tendência maior de queda nos países que já estavam com valores mais reduzidos em suas ligações internas. Já a Tabela 2 exibe os resultados obtidos para as medidas agregadas de ligações industriais e dos setores de serviços para os anos de 1995 e 2011, bem como a sua variação total no período.

${ }^{10}$ Para maiores detalhamentos sobre a construção das matrizes, ver Dietzenbacher et al., 2013. 
Uma primeira obervação permite perceber que em 1995, 29 dos 40 países da amostra já tinham as conexões dos serviços maiores do que as industriais, número que aumentou para 34 em 2011. Nota-se que 29 países apresentaram redução das conexões internas à indústria e 30 obtiveram aumento nas interconexões dos setores de serviços. Ainda, dos 10 países que tiveram redução nessa última variável, em 4 a redução foi inferior a $2 \%$, e 9 mostraram queda também no índice para as ligações industriais. Dessa forma, é possível afirmar que se está verificando atualmente um aumento na integração dos serviços com o restante da economia, simultaneamente a uma redução da integração dos setores industriais dentro dos países.

Finalmente, na comparação das duas variáveis com o PIB per capita, observa-se que a divisão também parece aleatória. No caso industrial, dos 20 países com índice de integração mais elevado, 11 estão também entre os mais ricos. Já nos serviços, a relação aponta para 9 países. Assim, tanto para medida agregada total, quanto para as que consideram apenas as interconexões industriais ou as conexões dos setores de serviços, não parece haver alguma relação mais notável. 
Tabela 1 - Medida agregada de ligações, sua variação e taxa de crescimento médio anual do PIB per capita nos países selecionados: 1995 - 2011

\begin{tabular}{|c|c|c|c|c|c|c|}
\hline \multirow{3}{*}{ País } & \multicolumn{4}{|c|}{ Medida agregada de ligações } & \multicolumn{2}{|c|}{ PIB per capita } \\
\hline & \multicolumn{2}{|c|}{ Ano } & \multirow{2}{*}{ Variação } & \multirow{2}{*}{ Posição em 2011} & \multirow{2}{*}{ Posição em 2011} & \multirow{2}{*}{ Variação anual média } \\
\hline & 1995 & 2011 & & & & \\
\hline China & 0,5578 & 0,5970 & 0,0391 & 1 & 37 & 9,08 \\
\hline Áustria & 0,3400 & 0,5385 & 0,1985 & 2 & 7 & 1,73 \\
\hline Coreia do Sul & 0,4645 & 0,5006 & 0,0361 & 3 & 18 & 3,97 \\
\hline Japão & 0,4862 & 0,4841 & $-0,0021$ & 4 & 14 & 0,59 \\
\hline Rússia & 0,4254 & 0,4620 & 0,0367 & 5 & 34 & 4,01 \\
\hline Portugal & 0,4075 & 0,4576 & 0,0501 & 6 & 23 & 1,28 \\
\hline Turquia & 0,3437 & 0,4497 & 0,1060 & 7 & 31 & 2,79 \\
\hline República Tcheca & 0,4662 & 0,4466 & $-0,0196$ & 8 & 26 & 2,56 \\
\hline Bulgária & 0,4031 & 0,4393 & 0,0363 & 9 & 37 & 3,75 \\
\hline Espanha & 0,4327 & 0,4351 & 0,0023 & 10 & 17 & 1,53 \\
\hline Austrália & 0,4465 & 0,4343 & $-0,0122$ & 11 & 13 & 2,00 \\
\hline Índia & 0,4757 & 0,4299 & $-0,0458$ & 12 & 40 & 5,38 \\
\hline Romênia & 0,4646 & 0,4267 & $-0,0379$ & 13 & 35 & 3,18 \\
\hline Eslováquia & 0,4526 & 0,4226 & $-0,0299$ & 14 & 25 & 4,25 \\
\hline Letônia & 0,3412 & 0,4213 & 0,0801 & 15 & 33 & 5,62 \\
\hline Itália & 0,4234 & 0,4200 & $-0,0034$ & 16 & 16 & 0,58 \\
\hline França & 0,4125 & 0,4130 & 0,0005 & 17 & 15 & 1,20 \\
\hline Malta & 0,2547 & 0,4123 & 0,1575 & 18 & 24 & 1,94 \\
\hline Finlândia & 0,4010 & 0,4084 & 0,0074 & 19 & 8 & 2,46 \\
\hline Estônia & 0,3652 & 0,4023 & 0,0371 & 20 & 28 & 5,21 \\
\hline Brasil & 0,4144 & 0,3992 & $-0,0152$ & 21 & 36 & 1,80 \\
\hline Estados Unidos & 0,4305 & 0,3931 & $-0,0373$ & 22 & 5 & 1,47 \\
\hline Canadá & 0,3433 & 0,3894 & 0,0461 & 23 & 12 & 1,60 \\
\hline Polônia & 0,4395 & 0,3873 & $-0,0522$ & 24 & 29 & 4,40 \\
\hline Suécia & 0,3855 & 0,3871 & 0,0016 & 25 & 4 & 2,16 \\
\hline Eslovênia & 0,3915 & 0,3857 & $-0,0058$ & 26 & 22 & 2,83 \\
\hline Bélgica & 0,3796 & 0,3840 & 0,0044 & 27 & 11 & 1,40 \\
\hline Dinamarca & 0,3499 & 0,3742 & 0,0242 & 28 & 2 & 1,05 \\
\hline Alemanha & 0,3879 & 0,3712 & $-0,0167$ & 29 & 10 & 1,37 \\
\hline Indonésia & 0,4153 & 0,3699 & $-0,0454$ & 30 & 39 & 2,40 \\
\hline Irlanda & 0,4570 & 0,3691 & $-0,0879$ & 31 & 3 & 3,13 \\
\hline Reino Unido & 0,3963 & 0,3632 & $-0,0331$ & 32 & 9 & 1,61 \\
\hline Taiwan & 0,3624 & 0,3401 & $-0,0223$ & 33 & 20 & 2,83 \\
\hline Holanda & 0,3470 & 0,3384 & $-0,0086$ & 34 & 6 & 1,73 \\
\hline Hungria & 0,4042 & 0,3358 & $-0,0684$ & 35 & 27 & 2,53 \\
\hline Chipre & 0,2522 & 0,3273 & 0,0752 & 36 & 19 & 1,29 \\
\hline Grécia & 0,3543 & 0,3079 & $-0,0464$ & 37 & 21 & 1,38 \\
\hline Lituânia & 0,3684 & 0,3063 & $-0,0621$ & 38 & 30 & 5,68 \\
\hline México & 0,3265 & 0,2845 & $-0,0420$ & 39 & 32 & 1,51 \\
\hline Luxemburgo & 0,2031 & 0,2507 & 0,0476 & 40 & 1 & 2,20 \\
\hline
\end{tabular}

Fonte: Elaboração própria. 
Tabela 2 - Variação das medidas agregadas de ligação dentro da indústria e dos setores de serviços entre 1995 e 2011

\begin{tabular}{|c|c|c|c|c|c|c|}
\hline \multirow{3}{*}{ País } & \multicolumn{3}{|c|}{ MAL IND } & \multicolumn{3}{|c|}{ MAL SER } \\
\hline & \multicolumn{2}{|c|}{ Ano } & \multirow{2}{*}{ Variação } & \multicolumn{2}{|c|}{ Ano } & \multirow{2}{*}{ Variaçãa } \\
\hline & 1995 & 2011 & & 1995 & 2011 & \\
\hline Alemanha & 0,2182 & 0,2082 & $-0,0100$ & 0,3745 & 0,3549 & $-0,0196$ \\
\hline Austrália & 0,2468 & 0,1734 & $-0,0734$ & 0,4002 & 0,4043 & 0,0041 \\
\hline Áustria & 0,1774 & 0,1705 & $-0,0069$ & 0,3129 & 0,5377 & 0,2248 \\
\hline Bélgica & 0,1430 & 0,1074 & $-0,0355$ & 0,3669 & 0,3789 & 0,0120 \\
\hline Brasil & 0,2925 & 0,2175 & $-0,0750$ & 0,2920 & 0,2942 & 0,0022 \\
\hline Bulgária & 0,2784 & 0,2401 & $-0,0383$ & 0,2768 & 0,3886 & 0,1118 \\
\hline Canadá & 0,2008 & 0,3073 & 0,1065 & 0,2813 & 0,3112 & 0,0299 \\
\hline China & 0,4268 & 0,4799 & 0,0532 & 0,3147 & 0,3677 & 0,0530 \\
\hline Chipre & 0,2424 & 0,3050 & 0,0626 & 0,1930 & 0,2728 & 0,0798 \\
\hline Coreia do Sul & 0,4329 & 0,4803 & 0,0474 & 0,2895 & 0,3235 & 0,0341 \\
\hline Dinamarca & 0,1695 & 0,1260 & $-0,0435$ & 0,3225 & 0,3621 & 0,0396 \\
\hline Eslováquia & 0,2615 & 0,1348 & $-0,1267$ & 0,3837 & 0,4150 & 0,0313 \\
\hline Eslovênia & 0,2044 & 0,1921 & $-0,0122$ & 0,3534 & 0,3703 & 0,0170 \\
\hline Espanha & 0,2765 & 0,2752 & $-0,0012$ & 0,3644 & 0,3993 & 0,0348 \\
\hline Estados Unidos & 0,3299 & 0,2545 & $-0,0754$ & 0,3293 & 0,3780 & 0,0487 \\
\hline Estônia & 0,1786 & 0,1301 & $-0,0484$ & 0,3041 & 0,3927 & 0,0885 \\
\hline Finlândia & 0,2934 & 0,2398 & $-0,0536$ & 0,2970 & 0,3571 & 0,0600 \\
\hline França & 0,2017 & 0,2786 & 0,0769 & 0,3763 & 0,3802 & 0,0040 \\
\hline Grécia & 0,2667 & 0,2535 & $-0,0132$ & 0,2919 & 0,2744 & $-0,0175$ \\
\hline Holanda & 0,1232 & 0,1217 & $-0,0014$ & 0,3315 & 0,3300 & $-0,0015$ \\
\hline Hungria & 0,2976 & 0,1596 & $-0,1380$ & 0,3000 & 0,2915 & $-0,0085$ \\
\hline Índia & 0,3644 & 0,3096 & $-0,0548$ & 0,3248 & 0,3211 & $-0,0037$ \\
\hline Indonésia & 0,3923 & 0,3126 & $-0,0797$ & 0,3963 & 0,2933 & $-0,1030$ \\
\hline Irlanda & 0,2366 & 0,3376 & 0,1010 & 0,4557 & 0,3494 & $-0,1063$ \\
\hline Itália & 0,2863 & 0,2298 & $-0,0565$ & 0,3473 & 0,3807 & 0,0335 \\
\hline Japão & 0,4283 & 0,4163 & $-0,0120$ & 0,3381 & 0,3651 & 0,0270 \\
\hline Letônia & 0,2540 & 0,1878 & $-0,0662$ & 0,2725 & 0,4037 & 0,1312 \\
\hline Lituânia & 0,1274 & 0,1223 & $-0,0050$ & 0,3115 & 0,2836 & $-0,0280$ \\
\hline Luxemburgo & 0,0565 & 0,0808 & 0,0243 & 0,2012 & 0,2490 & 0,0479 \\
\hline Malta & 0,1544 & 0,2374 & 0,0830 & 0,2292 & 0,4115 & 0,1824 \\
\hline México & 0,2748 & 0,1648 & $-0,1101$ & 0,2325 & 0,2338 & 0,0013 \\
\hline Polônia & 0,2660 & 0,1890 & $-0,0770$ & 0,3406 & 0,3392 & $-0,0014$ \\
\hline Portugal & 0,2603 & 0,2954 & 0,0351 & 0,3760 & 0,4469 & 0,0709 \\
\hline Reino Unido & 0,2212 & 0,1492 & $-0,0719$ & 0,3568 & 0,3528 & $-0,0040$ \\
\hline República Tcheca & 0,2658 & 0,2312 & $-0,0345$ & 0,4076 & 0,4200 & 0,0124 \\
\hline Romênia & 0,2429 & 0,2260 & $-0,0169$ & 0,3696 & 0,3759 & 0,0063 \\
\hline Rússia & 0,2353 & 0,1803 & $-0,0550$ & 0,3255 & 0,3597 & 0,0342 \\
\hline Suécia & 0,2087 & 0,2144 & 0,0056 & 0,3443 & 0,3521 & 0,0077 \\
\hline Taiwan & 0,3322 & 0,3072 & $-0,0249$ & 0,2292 & 0,2394 & 0,0102 \\
\hline Turquia & 0,3325 & 0,3724 & 0,0399 & 0,2242 & 0,4323 & 0,2081 \\
\hline
\end{tabular}

Fonte: Elaboração própria. 
Para auxiliar na busca por algum padrão, foi construída uma matriz de coeficiente de correlação de Pearson. ${ }^{11}$ Os resultados estão apresentados na Tabela 3. Nota-se em princípio que, segundo os índices de correlação, se existir alguma relação do PIB per capita de um país com o seu total de conexões intersetoriais, essa relação é inversa, dado o coeficiente de $-0,2553$. O mesmo padrão se mantém para as conexões primárias $(-0,2299)$ e industriais $(-0,3360)$, enquanto que para os serviços a relação é positiva $(0,0859)$, embora todos esses valores não sejam elevados. Assim, segundo esses dados, enquanto não há indícios da relação positiva entre o PIB per capita e as ligações de um país, também encontra-se evidência de perdas de conexões dentro da indústria e maior integração dos serviços com o restante da economia nos países conforme se aumenta o PIB per capita. Quanto ao crescimento dessa última variável, os valores para correlação também são pequenos, mas dão pistas de relação positiva com a presença de ligações dentro dos setores primários e da indústria, e negativa nos serviços. Ao notar a correlação negativa entre o PIB per capita e sua variação, pode-se fazer a associação de que os países mais pobres são os que apresentam taxas de crescimento maior, e esses estariam usando a estratégia de fomentar linkages para atingir tal objetivo, justificando o resultado acima.

Tabela 3 - Matriz de correlação para as variáveis de PIB per capita, medidas agregadas de ligação totais, primárias, industriais e de serviços, e variação do PIB per capita

\begin{tabular}{|l|cccccc|}
\hline & PIBPC & MAL TOT & MAL AGR & MAL IND & MAL SER & VAR PIB PC \\
\hline PIBPC & 1,0000 & & & & & \\
MAL TOT & $-0,2553$ & 1,0000 & & & & \\
MAL AGR & $-0,2299$ & 0,0275 & 1,0000 & & & \\
MAL IND & $-0,3360$ & 0,6009 & $-0,0536$ & 1,0000 & & \\
MAL SER & 0,0859 & 0,6702 & $-0,0428$ & $-0,0015$ & 1,0000 & \\
VAR PIB PC & $-0,2618$ & 0,1277 & 0,1334 & 0,0878 & $-0,0469$ & 1,0000 \\
\hline
\end{tabular}

Fonte: Elaboração própria.

11 Definido por: $\rho=\frac{\sum_{i=1}^{n}\left(x_{i}-\bar{x}\right) x\left(y_{i}-\bar{y}\right)}{\sqrt{\sum_{i=1}^{n}\left(x_{i}-\bar{x}\right)^{2}} \sqrt{\sum_{i=1}^{n}\left(y_{i}-\bar{y}\right)^{2}}}=\frac{\operatorname{cov}(X, Y)}{\sqrt{\operatorname{var}(x) \operatorname{var}(Y)}}$ 


\subsection{Análise de Agrupamentos}

Apesar de alguns resultados terem sido estabelecidos com a análise anterior, por exemplo, a queda nas ligações industriais nos países, concomitantemente com o aumento da integração dos serviços com o restante da economia, houve dificuldade de se estabelecer uma relação entre o PIB per capita e o total de interconexões setoriais nos países. A análise de agrupamentos permitá dividir os países em grupos de acordo com o tamanho de sua economia e suas medidas agregadas de ligações, podendo assim, evidenciar outras relações entre as variáveis. ${ }^{12}$

A avaliação sobre planejamento e do dendograma de aglomerações resultante da aplicação desse método dispostos no anexo III e IV respectivamente, onde podem ser visualizadas as medidas de similaridades conforme novos agrupamentos são realizados, permite notar que o maior salto relativo significativo aconteceu no $36^{\circ}$ estágio (de 13,7 para 23,3 , ou $70,1 \%$ de aumento) e, por isso, o número indicado é de 5 agrupamentos. No Quadro 1, que apresenta esses clusters, um primeiro ponto a ser observado é que Luxemburgo aparece sozinho em um grupo. Isso acontece porque seu PIB per capita é muito maior que o dos demais países, ao mesmo tempo em que possui o menor índice para ligações totais. Como pouca informação seria extraída da análise desse grupo, ele será deixado de lado na investigação a seguir.

Seguindo os agrupamentos, também é possível verificar que no primeiro cluster estão países sabidamente mais ricos, pertencentes à Europa Central, Escandinávia, Oceania e América do Norte. O grupo de número 2, por sua vez, tem como representantes países do Leste Asiático e a Áustria. No terceiro e no quarto agrupamentos encontram-se países de menor renda. Sendo heterogêneos em sua formação, estão países da periferia europeia, Ásia, México e Brasil.

12 Para a comprovação da possibilidade de clusterizar dados foram realizados o teste de Hopkins e uma avaliação visual de tendência de clusterização. O primeiro teste calcula a probabilidade de o conjunto de dados ter sido gerado aleatoriamente em uma distribuição uniforme. Caso o valor da estatística resultante se aproxime de 0,5 , essa hipótese não é rejeitada, e os dados não apresentam clusters significativos. Tendo sido realizadas diversas simulações, os resultados para os dados do artigo mostraram valores consistentemente diferentes de 0,5 . O segundo teste é visual e usa matrizes de dissimilaridade. Na imagem resultante, o número de quadrados bem definidos indica a existência de clusters e uma estimativa de sua quantidade. Os autores se colocam à disposição para enviar os resultados de ambos os testes. 
Quadro 1 - Formação dos agrupamentos segundo as variáveis de PIB per capita ${ }^{13}$ e MAL total

\begin{tabular}{|c|c|c|c|c|}
\hline \multicolumn{5}{|c|}{ Agrupamento } \\
\hline 1 & 2 & 3 & 4 & 5 \\
\hline 1 Austrália & 1 Áustria & 1 Bulgária & 1 Chipre & 1 Luxemburgo \\
\hline 2 Bélgica & 2 China & 2 Brasil & 2 Grécia & \\
\hline 3 Canadá & 3 Japão & 3 República Tcheca & 3 Hungria & \\
\hline 4 Alemanha & 4 Coreia do Sul & 4 Espanha & 4 Lituânia & \\
\hline 5 Dinamarca & & 5 Estônia & 5 México & \\
\hline 6 Finlândia & & 6 Indonésia & 6 Taiwan & \\
\hline 7 França & & 7 Índia & & \\
\hline 8 Reino Unido & & 8 Letônia & & \\
\hline 9 Irlanda & & 9 Malta & & \\
\hline 10 Itália & & 10 Polônia & & \\
\hline 11 Holanda & & 11 Portugal & & \\
\hline 12 Suécia & & 12 Romênia & & \\
\hline 13 Estados Unidos & & 13 Rússia & & \\
\hline & & 14 Eslováquia & & \\
\hline & & 15 Eslovênia & & \\
\hline & & 16 Turquia & & \\
\hline
\end{tabular}

Fonte: Elaboração própria.

A Tabela 4 exibe as estatísticas descritivas para os grupos de 1 a 4 e a média geral. O primeiro agrupamento é formado por países Centro-Europeus, Norte Americanos e pela Austrália, notoriamente de PIB per capita mais elevado, com média de US\$ 40,5 mil, bastante acima do geral (US\$ 24,5 mil). Quanto às suas medidas agregadas de ligação, nenhuma difere estatisticamente $^{14}$ da média de todos os países. Ainda assim, esses valores serão ressaltados, já que por se tratar de um dos maiores grupos (junto ao terceiro), é natural que o valor de sua média se aproxime da média geral. No caso, tal característica demonstra a maior importância de fazer as comparações entre os grupos, ao invés de uma média global. Desta forma, a MAL total deste grupo, além de estar ligeiramente abaixo da média geral $(0,388$ contra 0,401$)$, é apenas a terceira quando comparada aos demais agrupamentos, sendo inferior aos dois primeiros colocados $(0,530$ do gru-

${ }^{13}$ A validação dos resultados foi feita por meio de testes de sensibilidade empregando outras metodologias para clusterização. Em uma primeira avaliação, foi utilizado um modelo finito de distribuições mistas, usando matriz de covariância Gaussiana, ajustado por um algoritmo de maximização de expectativa (Fraley et al., 2012). Uma segunda análise empregou, na etapa hierárquica, uma matriz de dissimilaridades baseada em correlações. Os resultados iniciais se mostraram robustos na medida em que, apesar de algumas diferenças, os grupos se mostraram semelhantes, não impactando a conclusão final do estudo. Os autores colocam-se à disposição para o envio destes resultados, em caso de solicitação.

14 Testes t para igualdade entre médias tiveram sua hipótese nula rejeitada ao nível de 5\%. 
po 2 e 0,421 do grupo 3). Padrão semelhante segue na comparação das conexões dos setores de serviços, embora nesse caso já não haja diferença significativa entre esses 3 primeiros colocados, assim como em relação a média $(0,360$ para o grupo 1 contra 0,354 da média geral).

Em relação ao setor agricultura, as médias de todos os grupos foram muito próximas, sem diferença estatística entre elas. Ainda assim, o primeiro agrupamento ficou com a última colocação nessa variável $(0,096)$, posição que se repetiu nos setores industriais $(0,211)$ e no crescimento do PIB per capita $(1,67 \%)$. Percebe-se, portanto, que apesar de o grupo 1 ser de países de renda mais elevada, não há nenhum destaque quanto as suas interconexões setoriais ou no seu desempenho de crescimento.

Tabela 4 - Estatísticas descritivas dos agrupamentos formados com base nas variáveis de PIB per capita e MAL total

\begin{tabular}{|c|c|c|c|c|c|}
\hline Agrupamento & Variável & Mínimo & Máximo & Média & Desvio Padrão \\
\hline \multirow[t]{6}{*}{$\overline{1}$} & PIB PC & $30.915,23$ & $48.143,83$ & $40.529,81$ & $5.141,65$ \\
\hline & MAL & 0,3384 & 0,4343 & 0,3881 & 0,0261 \\
\hline & MAL AGR & 0,0142 & 0,1758 & 0,0969 & 0,0483 \\
\hline & MAL IND & 0,1074 & 0,3376 & 0,2114 & 0,0731 \\
\hline & MAL SER & 0,3112 & 0,4043 & 0,3609 & 0,0242 \\
\hline & CM PPC & 0,58 & 3,13 & 1,67 & 0,65 \\
\hline \multirow[t]{6}{*}{2} & PIB PC & $3.121,97$ & $41.191,49$ & $25.850,16$ & $17.008,99$ \\
\hline & MAL & 0,4841 & 0,5970 & 0,5301 & 0,0501 \\
\hline & MAL AGR & 0,0656 & 0,1912 & 0,1223 & 0,0533 \\
\hline & MAL IND & 0,1705 & 0,4803 & 0,3868 & 0,1473 \\
\hline & MAL SER & 0,3235 & 0,5377 & 0,3985 & 0,0950 \\
\hline & CM PPC & 0,59 & 9,08 & 3,84 & 3,76 \\
\hline \multirow[t]{6}{*}{3} & PIB PC & $1.086,05$ & $25.937,24$ & $10.878,10$ & $6.985,67$ \\
\hline & MAL & 0,3699 & 0,4620 & 0,4217 & 0,0271 \\
\hline & MAL AGR & 0,0351 & 0,2649 & 0,1267 & 0,0569 \\
\hline & MAL IND & 0,1301 & 0,3724 & 0,2332 & 0,0665 \\
\hline & MAL SER & 0,2933 & 0,4469 & 0,3790 & 0,0467 \\
\hline & CM PPC & 1,28 & 5,62 & 3,31 & 1,40 \\
\hline \multirow[t]{6}{*}{4} & PIB PC & $8.307,69$ & $22.663,48$ & $15.339,81$ & $6.265,11$ \\
\hline & MAL & 0,2845 & 0,3401 & 0,3170 & 0,0212 \\
\hline & MAL AGR & 0,0611 & 0,1902 & 0,1218 & 0,0531 \\
\hline & MAL IND & 0,1223 & 0,3072 & 0,2187 & 0,0802 \\
\hline & MAL SER & 0,2338 & 0,2915 & 0,2659 & 0,0237 \\
\hline & CM PPC & 1,29 & 5,68 & 2,54 & 1,67 \\
\hline \multirow[t]{6}{*}{ Total } & PIB PC & $1.086,05$ & $81.852,98$ & $24.455,74$ & 17.703 \\
\hline & MAL & 0,2507 & 0,5970 & 0,4016 & 0,0659 \\
\hline & MAL AGR & 0,0142 & 0,2649 & 0,1167 & 0,0526 \\
\hline & MAL IND & 0,0808 & 0,4803 & 0,2355 & 0,0951 \\
\hline & MAL SER & 0,2338 & 0,5377 & 0,3548 & 0,0611 \\
\hline & CM PPC & 0,58 & 9,08 & 2,69 & 1,72 \\
\hline
\end{tabular}

Fonte: Elaboração própria. 
O segundo grupo é formado por 3 países do leste asiático (China, Coreia do Sul e Japão) e pela Áustria. Apesar de ter, em média, o seu produto per capita (US\$ 25,9 mil) um pouco acima do nível geral, este se distingue dos demais devido ao valor elevado de sua medida agregada de ligações totais $(0,53)$, influenciado principalmente pelas interconexões dos seus setores industriais $(0,39)$. Ambas as medidas são as maiores dentre todos os grupos, assim como o crescimento médio do PIB per capita desses países $(3,84 \%)$. Assim, apesar de ter um nível de renda intermediário, esse grupo se caracteriza por ter elevados índices de ligação e desempenho de crescimento.

Os grupos 3 e 4 são ambos compostos de países com menor produto per capita médio e, por isso, devem ser comentados conjuntamente. Se por um lado o grupo de número 4 supera o terceiro grupo nessa última variável (US $\$ 15.3$ mil contra US $\$ 10,9$ mil), em termos de MAL total ele se encontra em desvantagem $(0,317$ contra 0,421$)$. A diferença se dá, em maior grau, nas interconexões dos setores de serviços $(0,379$ contra 0,265$)$, mas também há vantagem (insignificante em termos estatísticos) na indústria $(0,235$ contra 0,218$)$. Por fim, nota-se ainda o melhor resultado de crescimento de PIB per capita para o terceiro agrupamento. Em suma, trata-se de dois grupos com países de renda baixa mas com diferenças em termos de interconexões, com valores intermediários para o grupo 3 e baixos no grupo 4.

Os resultados destacados com a análise da Tabela 4 mostram que não há uma relação direta entre o total de interconexões e o tamanho de uma economia. Os valores se mostram aleatórios; nota-se, por exemplo, que o agrupamento de maior PIB per capita tem apenas a terceira colocação entre os grupos em termos de MAL total, enquanto que o grupo de países de menor renda ocupa o segundo lugar em termos de ligações intersetoriais. Tal fato parece ser corroborado pela Figura 1, que fornece uma visualização dos dados por meio da dispersão da média dos grupos, em relação à média total para as variáveis de PIB per capita e MAL total. Nela, nota-se que cada agrupamento ocupou um quadrante distinto. 


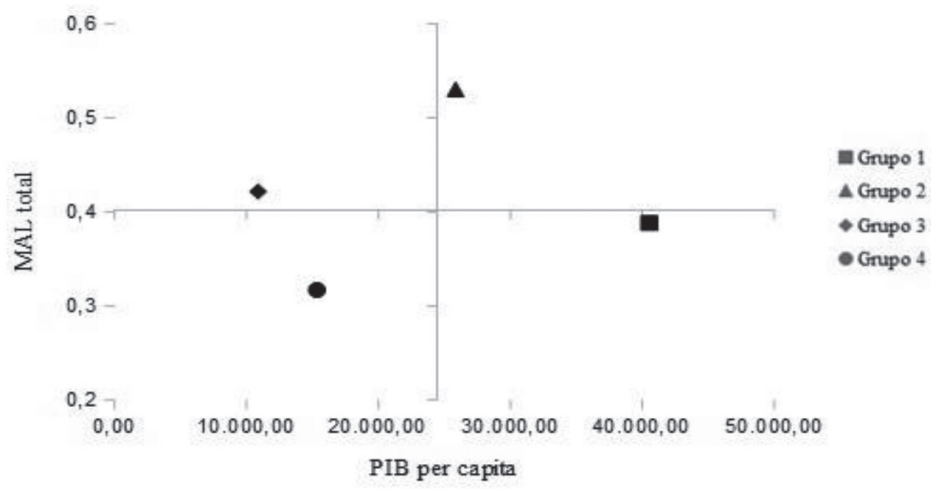

Figura 1 - Gráfico de dispersão com os valores referentes as médias dos grupos nas variáveis de PIB per capita e MAL total, em relação a média geral

Na Figura 2, países de um mesmo grupo estão representados pela mesma forma e localizadas ainda de acordo com seus valores de PIB per capita e MAL total. Com seu auxílio é possível identificar, por exemplo, que o grupo 2 é composto de países com setores mais conectados, o grupo 1 por países de renda mais elevada, e o grupo 3 e grupo 4 se diferem pelo seu nível de conexões, estando bem ajustados. Porém, quando se tenta identificar um padrão usando as duas variáveis, não há um padrão que corrobore as discussões teóricas.

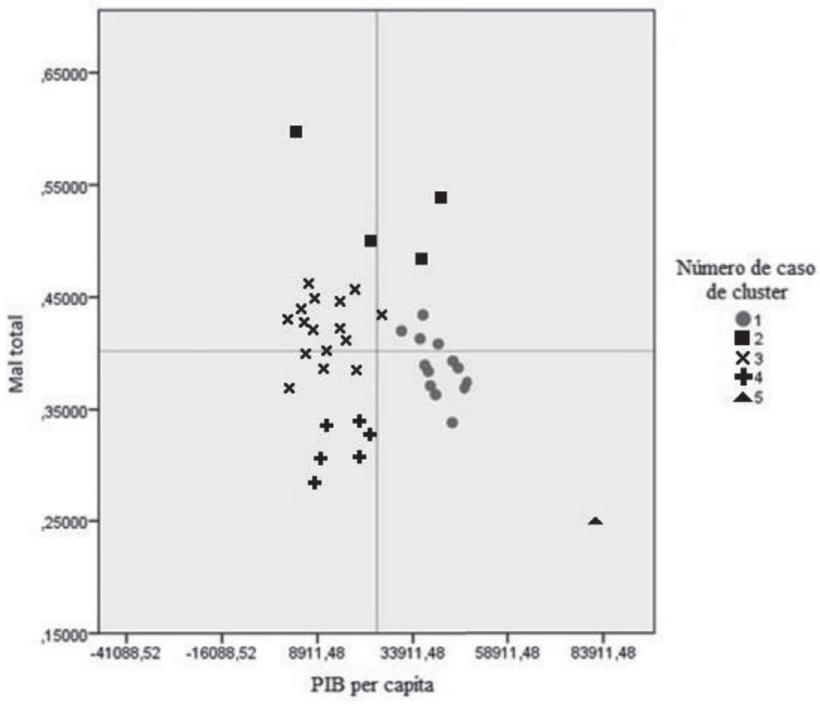

Figura 2 - Gráfico de dispersão para os países da amostra segundo as variáveis de PIB per capita e MAL total 
Por outro lado, ainda com os dados da Tabela 4, observam-se alguns indícios de relação entre as medidas de ligação e o crescimento do PIB per capita. Nota-se, principalmente para a desagregação dos setores industriais, que grupos com maiores níveis de interconexões apresentam desempenho de crescimento mais forte. Esse padrão se segue, mas em menor escala, para a MAL total e dos setores de serviços. De fato, com exceção dessa última, indícios sobre essas relações já foram adiantadas na Tabela 3, com os coeficientes de correlação. Com as informações auferidas nas análises, torna-se possível investigar qualificadamente os agrupamentos. No primeiro, estão contidos países ditos como desenvolvidos e com renda elevada. Seu valor para a MAL total, contudo, ficou em um nível intermediário abaixo da média. Esses países encontram-se já na fase descendente da "curva de u invertido" explícita por Rowthorn \& Coutts (2013). Assim, por estar em uma etapa de "desindustrialização positiva", não surpreende que seu total de ligações esteja abaixo da média, já que são países dos quais setores produtivos estão sendo segmentados para outros países, diminuindo sua integração vertical, o que se reflete também nas conexões dentro da indústria e nos setores primários, com o pior resultado dentre os grupos formados. Portanto, mais uma vez, esse grupo mostra evidências da impossibilidade de traçar relações dessas conexões com o PIB per capita de uma economia. Em relação às ligações dos serviços, apesar de estarem acima da média, a diferença não é significativa, mesmo estando em terceiro lugar dentro dos agrupamentos, o que impede de se estabelecer conclusões mais fortes, em comparação ao que era previsto para os países mais ricos, ou seja, a maior integração desses setores com o restante da economia, conforme Schettkat \& Yocarini (2006) e Maroto-Sanchez (2010).

O grupo de número 2 foi caracterizado por ter o PIB per capita um pouco acima da média e índice de ligações elevados. Outra característica marcante foi o valor para sua taxa de crescimento da renda per capita, puxada principalmente pela China e Coreia do Sul, o que foi acompanhado por altos valores para todas as desagregações das medidas de ligações, principalmente para a indústria e os serviços. Ainda com enfoque na China e na Coreia do Sul, esses são países conhecidos por receberem diversas fases de produção que antes se localizavam em países mais ricos, se fazendo valer dos fatores destacados por Feenstra (2002), Keller (2010) e Grossman \& Helpman (2002a, b), como seu menor custo de produção e da evolução nas tecnologias de transporte, comunicação e informação. 
O terceiro e o quarto agrupamentos, de países em geral mais pobres, exibiram características muito próximas, diferenciando-se principalmente pela superioridade do primeiro entre eles na integração dos serviços e no crescimento do PIB per capita. Esse melhor desempenho de crescimento é acompanhado por maior integração interna, não só nos serviços mas também na indústria. Esse resultado, conjuntamente com o que foi visto no grupo II, reforça a validade ainda atual da estratégia de crescimento via fomento às interconexões setoriais proposta por Perroux (1955), Chenery \& Watanabe (1958) e Hirschman (1958). Tomando como exemplo o grupo 3 , nota-se que seus países têm uma posição de fornecedores para os países dos outros grupos, seja em bens agrícolas, commodities ou energéticos. Assim, não surpreende que seus setores primários sejam mais integrados que os demais. Ainda, por se tratar de países na fase crescente da "curva de u invertido", entende-se porque a seu crescimento é maior do que a do primeiro agrupamento, o que é também consequência de estratégias industrializantes, embora em menor grau do que acontece nos países do segundo grupo.

\section{Conclusões}

Este artigo buscou aprofundar a investigação das possíveis relações entre o PIB per capita dos países e o seu agregado de ligações intersetoriais em um ambiente de mudanças estruturais nas economias. $\mathrm{O}$ uso do método autovetor como meio para o cálculo de uma medida agregada de ligações elucidou algumas transformações importantes, em especial o crescimento da integração dos serviços com o restante da economia, enquanto os setores primários e manufatureiros mostram cada vez menor integração interna, em consonância com a evolução destacada.

Apesar disso, não foi possível estabelecer apenas visualmente padrões de relação entre as medidas agregadas de ligação e o nível do PIB per capita dos países. tornando-se necessário o uso da análise de agrupamentos. Através dela, foi possível verificar a relação entre as interconexões industriais e o crescimento do PIB per capita. Também há alguns indícios de relação direta entre o nível de integração dos setores de serviços de um país com o seu PIB per capita e sua taxa de crescimento. Ainda, em geral, essas ligações já são mais fortes do que as dos demais setores. Por outro 
lado, quanto às conexões totais e o nível de PIB per capita, nenhuma evidência de relação foi encontrada.

Assim, conclui-se que a estratégia proposta por Hirschman (1958) para obter crescimento econômico, em destaque a formação de interconexões entre os setores industriais via uso intermediário, ainda é atual, mesmo após as mudanças estruturais nas economias. Contudo, os caminhos trilhados pelas economias em seu curso de crescimento têm mostrado que, a partir de um certo ponto (associado a um nível de PIB per capita), a indústria começa a perder importância relativa, em detrimento do desenvolvimento dos setores de serviços. Com a saída da indústria, em especial com os processos de segmentação da produção, a tendência natural é a queda no uso intermediário provido por fontes internas, o que é sinônimo de perda de interconexões. Os países com maior PIB per capita, por outro lado, têm mostrado o aumento da integração dos setores de serviços com o restante da economia. Ainda assim, esse movimento não tem se mostrado suficiente para manter o total das ligações desses países no mesmo patamar de antes. Por isso, a dificuldade de se estabelecer uma relação direta entre o nível do PIB per capita de um país e o seu total de conexões intersetoriais. Portanto, é importante em termos de formulação de política, que os países levem em consideração o estágio de desenvolvimento em que eles se encontram.

Uma possível extensão para esse artigo poderia apreciar a relação entre o crescimento econômico dos países não só com as interconexões internas, mas também com as ligações existentes com os países vizinhos, levando em consideração tratados comerciais como os existentes na União Europeia e no Mercosul. A integração de um país com o ambiente ao seu redor deve ser um ponto decisivo para entender o crescimento econômico no cenário atual. 


\section{Referências}

Banco Mundial (World Bank). Acesso em: 21 de fev. 2018. http://www.worldbank.org/.

Baumol, W. 1967. "Macroeconomic of Unbalanced Growth: The Anatomy of Urban Crisis." American Economic Review 57 (3): 415-426.

Botric, V. 2013. "Identifying Key Sectors in Croatian Economy Based on Input-Output Tables”, Working Papers 1302, The Institute of Economics, Zagreb.

Capello, R., Fratesi, U. 2013. "The Service Sector in the New Globalization Phase: Evidence from European Regions.” In J. R. Cuadrado-Roura (Eds.). Service, Industries and Regions: Growth, Location and Regional Effects. Berlim: Springer-Verlag.

Cuadrado-Roura, J. R. 2013. "Introduction: Objectives, Approach and Main Lessions Learned." In J. R. CuadradoRoura (Eds.). Service, Industries and Regions: Growth, Location and Regional Effects. Berlim: Springer-Verlag.

Cuadrado-Roura, J. R. 2013. “Towards Increasingly ‘Tertiarised' Economies: Facts, Factors and Prospects.” In J. R. Cuadrado-Roura (Eds.). Service, Industries and Regions: Growth, Location and Regional Effects. Berlim: Springer-Verlag.

Chenery, H. B., Watanabe, T. 1958. "International Comparisions of the Structure of Production." Econometrica 26: 487-521.

Dietzenbacher, E. 1991. "Pertubations and Eigenvectors - Essays." Tese de pós-Doutorado, Universidade de Groningen.

Dietzenbacher, E. 1992. "The Measurement of Interindustry linkages: Key Sectors in the Netherlands.” Economic Modeling, Elsevier, 9 (4): 419-437.

Dietzenbacher, E., Los, B., Stehrer, R., Timmer, M., De Vries, G. 2013. “The Construction of World Input-Output Tables in the WIOD Project." Economic Systems Research 25 (1): 71-98.

Fraley, C., Raftery, A. E., Murphy, B., Scrucca, L. 2012. "mclust Version 4 for R: Normal Mixture Modeling for Model-Based Clustering, Classification, and Density Estimation." Technical Report 597, Department of Statistics, University of Washington.

Feenstra, R. C. 1998. "Integration of Trade and Disintegration of Production in the Global Economy." Journal of Economic Perspectives 12 (4): 31-50.

Feenstra, R. C. 2002. “Advanced International Trade: Theory and Evidence.” Princeton: Princeton University Press. Garcilazo, E., Mouradian, F., Oliveira-Martins, J. 2013 "Patterns and Trends in Services Related Activities." In J. R. Cuadrado-Roura (Eds.). Service, Industries and Regions: Growth, Location and Regional Effects. Berlim: Springer-Verlag.

Grossman, G. M., Helpman, E. (2002a). "Integration versus Outsourcing in Industry.” Quaterly Journal of Economics 117 (1): 85-120.

Grossman, G. M., Helpman, E. (2002b). "Outsourcing in a Global Economy." Review of Economic Studies 72: 135-159.

Hirschman, A. O., 1958. "The Strategy of Economic Development”. Yale: Yale University Press.

Kaldor, N. 1961. "Capital Accumulation and Economic Growth.” In F. A. Lutz \& D. C. Hague. The Theory of Capital, New York: St. Martins Press.

Keller, W. 2010. “International Trade, Foreign Direct Investment, and Technology Spillovers.” In B. H. Hall, N. Rosenberg (Eds). Handbook of the Economics of Innovation. Amsterdam: North Holland.

Kuznetz, S. 1971. "Economic Growth of Nations: Total Output and Production Structure." Cambridge: Harvard University Press.

Lopes, J. C., Dias, J. E., Amaral, J. F. 2008. “Assessing Economic Complexity with Input-Output Based Measures." Working papers 49, Instituto Superior de Economia e Gestão. 
Los, B., Timmer, M. P., De Vries, G. J. 2015. "How Global Are Global Value Chains? A New Approach to Measure International Fragmentation.” Journal of Regional Science 55 (1): 66-92.

Luo, J., 2013. "Which Industries to Bail out First in Economic Recession? Ranking US Industrial Sectors by the Power-of-Pull." Economic Systems Research 25 (2): 157-169.

Maddisson, A. 1980. "Economic Growth and Structural Change in the Advanced Countries". In I. Leveson (Eds.). Western Economies in Transition: Structural Change and Adjustment Policies in Industrial Countries. Boulder: Westview Press.

Markusen, J. R. 2002. "Multinational Firms and the Theory of International Trade”, Cambridge: MIT Press.

Maroto-Sánchez, A. 2010 "Growth and Productivity in the Service Sector: The State of the Art." Documentos de trabajo 07/2010, Univsersidad de Alcalá, Madrid.

Midmore, P., Munday, M., Roberts, A. 2006. “Assessing Industry Linkages Using Regional Input-Output Tables.” Regional Studies 40 (3): 329-343.

Organização Mundial do Comércio (OMC/WTO) 2014. “Annual Report 2014.” Geneva: World Trade Organization.

Perroux F. 1955. "Note sur la notion de 'pôle de croissance."” Economie Appliquée 8 (1-2): 307-320.

Rasmussen, P. N. 1956. "Studies in Intersectoral Relations.” Amsterdam: North-Holland.

Rowthorn, R., Coutts, K. 2013. "De-industrialization and the balance of payments in advanced economies." Future of Manufacturing Project: Evidence Paper 31, Cambridge University.

Rowthorn, R., Ramaswamy, R. 1997. "Deindustrialization: Causes and Implications." Working papers 42, International Monetary Fond.

Rowthorn, R., Ramaswamy, R. 1999. “Growth, Trade and Deindustrialization.” IMF Staff Papers 46 (1): 18-41.

Schettkat, R., Yocarini, L. 2006. "The Shift to Services Employment: A Review of the Literature.” Structural Change and Economic Dynamics 17: 127-147.

Seneta, E. 1981. "Non-negative Matrices and Markov Chains.”, 2a Ed, New York: Springer-Verlag.

Timmer, M. P., Los, B., Stehrer, R., De Vries, G. J. 2013. "Fragmentation, Incomes and Jobs: An Analysis of European Competitiveness." Economic Policy 28: 613-661.

Timmer, M. P., Dietzenbacher, E., Los, B., Stehrer, R., De Vries, G. J. 2015. “An Illustrated User Guide to the World Input-Output Database: the Case of Global Automotive Production." Review of International Economics 23: 575-605.

Weller, J. 2004. "El Empleo Terciario en America Latina: Entre la Modernidad y la Sobrevivencia." Revista de la CEPAL 84: 159-177.

Wölfl, A. 2005. "The Service Economy in OECD Countries." In: Organisation for Economic Cooperation and Development. Enhancing the Performance of the Service Sector. Paris: OECD, pags. 27-62.

World Iinput-Output Database (WIOD). Acesso em: 21 de fev. De 2017. http://www.wiod.org. 


\section{Anexos}

Anexo I - Lista de países incluídos nas WIOTs

\begin{tabular}{|lllll|}
\hline Alemanha & Chipre & França & Letônia & República Checa \\
Austrália & Coreia do Sul & Grécia & Lituânia & Romênia \\
Áustria & Dinamarca & Hungria & Luxemburgo & Rússia \\
Bélgica & Eslováquia & Índia & Malta & Suécia \\
Brasil & Eslovênia & Indonésia & México & Taiwan \\
Bulgária & Espanha & Irlanda & Holanda & Turquia \\
Canadá & Estônia & Itália & Polônia & Reino Unido \\
China & Finlândia & Japão & Portugal & Estados Unidos \\
\hline
\end{tabular}

\section{Anexo II - Lista de setores incluídos nas WIOTs}

1. Agricultura, caça, silvicultura e pesca
2. Exploração mineral e de pedreiras
3. Alimentos, bebidas e tabaco
4. Produtos têxteis
5. Couro e calçados
6. Madeira e produtos de madeira e cortiça
7. Celulose, papel, impressão e publicação
8. Coque, refino de petróleo e Combustível
nuclear
9. Produtos químicos
10. Borracha e plásticos
11. Outros minerais não metálicos
12. Metais básicos ou fabricados
13. Maquinarias
14. Equipamentos elétricos ou óticos
15. Equipamentos de transporte
16. Manufaturas e reciclagem
17. Eletricidade, gás e água
18. Construção

19. Venda, manutenção e reparo de veículos automotores e motocicletas; comércio a varejo de combustíveis

20. Comércio por atacado e por comissão, exceto de veículos automotores e motocicletas

21. Venda a varejo, exceto de veículos automotores e motocicletas; reparo de bens domésticos

22. Hotéis e restaurantes

23. Transporte terrestre

24. Transporte aquaviário

25. Transporte aério

26. Outras atividades de suporte ou auxílio aos transportes; atividades de agências de turismo

27. Correios e telecomunidações

28. Intermediação financeiras

29. Atividades imobiliárias

30. Aluguel de máquinas e equipamentos e outras atividades de negócios

31. Administração pública e defesa; seguridade social compulsória

32. Educação

33. Saúde e serviço social

34. Outros serviços comunitários, sociais e pessoais

35. Residências provadas com pessoal empregado

Fonte: World Input-Output Database. 
Anexo III - Planejamento de aglomeração para as variáveis de PIB per capita e medida agregada de ligações totais

\begin{tabular}{|c|c|c|c|c|c|c|c|c|}
\hline \multirow[b]{2}{*}{ Estágio } & \multicolumn{2}{|c|}{ Cluster combinado } & \multirow[b]{2}{*}{ Coeficientes } & \multicolumn{2}{|c|}{$\begin{array}{c}\text { O cluster de } \\
\text { estágio é exibido } \\
\text { primeiro }\end{array}$} & \multirow{2}{*}{$\begin{array}{l}\text { Próximo } \\
\text { estágio }\end{array}$} & \multirow{2}{*}{$\begin{array}{l}\text { Variação no } \\
\text { coeficiente }\end{array}$} & \multirow{2}{*}{$\begin{array}{l}\text { Variação } \\
(\%) \text { no } \\
\text { coeficiente }\end{array}$} \\
\hline & Cluster 1 & Cluster 2 & & Cluster 1 & Cluster 2 & & & \\
\hline 1 & 11 & 21 & 0,004 & 0 & 0 & 19 & - & \\
\hline 2 & 3 & 6 & 0,008 & 0 & 0 & 18 & 0,00 & 130,78 \\
\hline 3 & 37 & 40 & 0,015 & 0 & 0 & 19 & 0,01 & 89,00 \\
\hline 4 & 10 & 16 & 0,026 & 0 & 0 & 18 & 0,01 & 65,12 \\
\hline 5 & 27 & 33 & 0,036 & 0 & 0 & 16 & 0,01 & 41,69 \\
\hline 6 & 29 & 35 & 0,052 & 0 & 0 & 21 & 0,02 & 42,83 \\
\hline 7 & 34 & 38 & 0,074 & 0 & 0 & 23 & 0,02 & 43,50 \\
\hline 8 & 13 & 31 & 0,101 & 0 & 0 & 14 & 0,03 & 36,10 \\
\hline 9 & 8 & 39 & 0,130 & 0 & 0 & 20 & 0,03 & 28,91 \\
\hline 10 & 4 & 20 & 0,161 & 0 & 0 & 16 & 0,03 & 23,70 \\
\hline 11 & 14 & 15 & 0,200 & 0 & 0 & 17 & 0,04 & 23,91 \\
\hline 12 & 9 & 32 & 0,239 & 0 & 0 & 29 & 0,04 & 19,89 \\
\hline 13 & 25 & 28 & 0,296 & 0 & 0 & 31 & 0,06 & 23,82 \\
\hline 14 & 5 & 13 & 0,355 & 0 & 8 & 24 & 0,06 & 19,79 \\
\hline 15 & 12 & 22 & 0,421 & 0 & 0 & 27 & 0,07 & 18,45 \\
\hline 16 & 4 & 27 & 0,497 & 10 & 5 & 23 & 0,08 & 18,18 \\
\hline 17 & 1 & 14 & 0,588 & 0 & 11 & 27 & 0,09 & 18,23 \\
\hline 18 & 3 & 10 & 0,684 & 2 & 4 & 28 & 0,10 & 16,39 \\
\hline 19 & 11 & 37 & 0,788 & 1 & 3 & 26 & 0,10 & 15,16 \\
\hline 20 & 8 & 17 & 0,894 & 9 & 0 & 22 & 0,11 & 13,45 \\
\hline 21 & 29 & 36 & 1,078 & 6 & 0 & 29 & 0,18 & 20,63 \\
\hline 22 & 8 & 18 & 1,317 & 20 & 0 & 31 & 0,24 & 22,20 \\
\hline 23 & 4 & 34 & 1,564 & 16 & 7 & 32 & 0,25 & 18,70 \\
\hline 24 & 5 & 19 & 1,817 & 14 & 0 & 33 & 0,25 & 16,21 \\
\hline 25 & 23 & 24 & 2,132 & 0 & 0 & 30 & 0,31 & 17,30 \\
\hline 26 & 11 & 30 & 2,476 & 19 & 0 & 28 & 0,34 & 16,14 \\
\hline 27 & 1 & 12 & 2,820 & 17 & 15 & 34 & 0,34 & 13,92 \\
\hline 28 & 3 & 11 & 3,250 & 18 & 26 & 34 & 0,43 & 15,23 \\
\hline 29 & 9 & 29 & 3,815 & 12 & 21 & 32 & 0,57 & 17,39 \\
\hline 30 & 2 & 23 & 4,430 & 0 & 25 & 35 & 0,62 & 16,13 \\
\hline 31 & 8 & 25 & 5,140 & 22 & 13 & 37 & 0,71 & 16,03 \\
\hline 32 & 4 & 9 & 6,332 & 23 & 29 & 33 & 1,19 & 23,18 \\
\hline 33 & 4 & 5 & 7,669 & 32 & 24 & 37 & 1,34 & 21,12 \\
\hline 34 & 1 & 3 & 10,121 & 27 & 28 & 36 & 2,45 & 31,97 \\
\hline 35 & 2 & 7 & 13,691 & 30 & 0 & 38 & 3,57 & 35,28 \\
\hline 36 & 1 & 26 & 23,290 & 34 & 0 & 39 & 9,60 & 70,11 \\
\hline 37 & 4 & 8 & 34,332 & 33 & 31 & 38 & 11,04 & 47,41 \\
\hline 38 & 2 & 4 & 51,470 & 35 & 37 & 39 & 17,14 & 49,92 \\
\hline 39 & 1 & 2 & 78,000 & 36 & 38 & 0 & 26,53 & 51,54 \\
\hline
\end{tabular}

Fonte: Elaboração própria a partir de saída de softwares IBM SPSS Statistics 23. 
Anexo IV - Dendograma de agrupamentos para as variáveis de PIB per capita e medida agregada de ligações totais

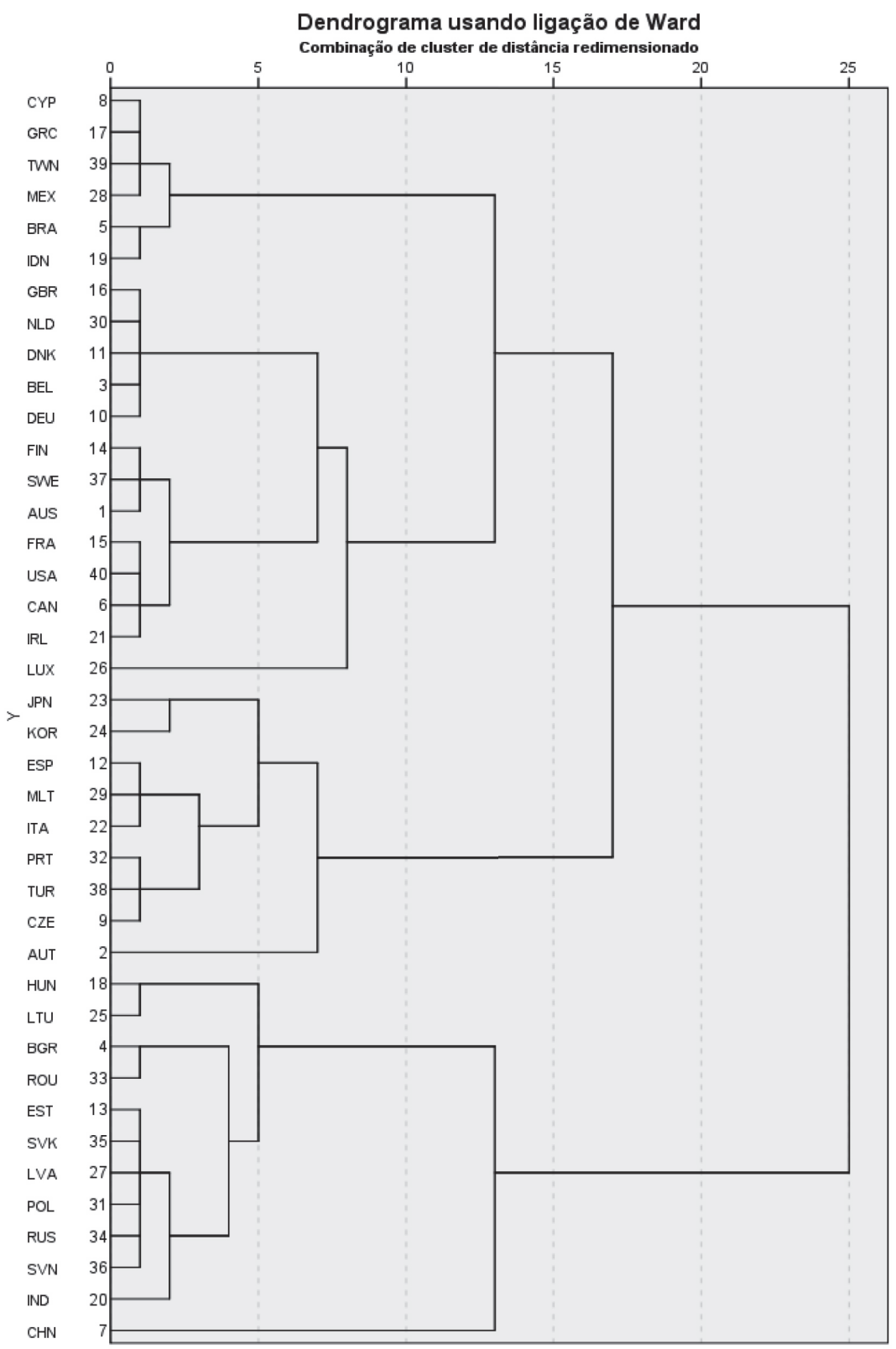

Fonte: Saída do software IBM SPSS Statistics 23. 